\title{
The long lifespan and low turnover of human islet beta cells estimated by mathematical modelling of lipofuscin accumulation
}

\author{
M. Cnop • S. J. Hughes • M. Igoillo-Esteve • M. B. Hoppa • F. Sayyed • \\ L. van de Laar • J. H. Gunter • E. J. P. de Koning • G. V. Walls • D. W. G. Gray • \\ P. R. V. Johnson • B. C. Hansen • J. F. Morris • M. Pipeleers-Marichal • I. Cnop • \\ A. Clark
}

Received: 8 June 2009 / Accepted: 24 August 2009 / Published online: 24 October 2009

(C) Springer-Verlag 2009

\begin{abstract}
Aims/hypothesis Defects in pancreatic beta cell turnover are implicated in the pathogenesis of type 2 diabetes by genetic markers for diabetes. Decreased beta cell neogenesis could contribute to diabetes. The longevity and turnover of human
\end{abstract}

Electronic supplementary material The online version of this article (doi:10.1007/s00125-009-1562-x) contains supplementary material, which is available to authorised users.

M. Cnop · M. Igoillo-Esteve

Laboratory of Experimental Medicine and Division of

Endocrinology, Université Libre de Bruxelles,

Brussels, Belgium

S. J. Hughes · D. W. G. Gray • P. R. V. Johnson

DRWF Islet Isolation Facility, Nuffield Department of Surgery,

Churchill Hospital, Oxford, UK

M. B. Hoppa · F. Sayyed - L. van de Laar · J. H. Gunter •

E. J. P. de Koning $\cdot$ A. Clark $(\bowtie)$

Diabetes Research Laboratories, Oxford Centre for Diabetes,

Endocrinology and Metabolism,

Churchill Hospital, Old Road,

Oxford OX3 7LJ, UK

e-mail: anne.clark@drl.ox.ac.uk

\section{G. V. Walls}

Academic Endocrine Unit, Oxford Centre for Diabetes,

Endocrinology and Metabolism,

Churchill Hospital, Oxford, UK

\section{B. C. Hansen}

Obesity, Diabetes and Aging Research Center,

College of Medicine, University of South Florida,

Tampa, FL, USA

\section{J. F. Morris}

Department of Physiology, Anatomy and Genetics,

University of Oxford, Oxford, UK beta cells is unknown; in rodents $<1$ year old, a half-life of 30 days is estimated. Intracellular lipofuscin body (LB) accumulation is a hallmark of ageing in neurons. To estimate the lifespan of human beta cells, we measured beta cell LB accumulation in individuals aged $1-81$ years.

M. Pipeleers-Marichal

Diabetes Research Centre, Vrije Universiteit Brussel,

Brussels, Belgium

I. Cnop

Department of Mathematics, Vrije Universiteit Brussel,

Brussels, Belgium

Present address:

F. Sayyed

Department of Surgery, Leicester Royal Infirmary,

Leicester, UK

Present address:

L. van de Laar

Department of Gastroenterology and Hepatology,

Erasmus University, Rotterdam, The Netherlands

Present address:

J. H. Gunter

Diamantina Institute for Cancer,

Immunology and Metabolic Medicine,

Princess Alexandra Hospital, University of Queensland,

Brisbane, QLD, Australia

Present address:

E. J. P. de Koning

Department of Nephrology C3-P,

Leiden University Medical Center,

Leiden, The Netherlands 
Methods LB content was determined by electron microscopical morphometry in sections of beta cells from human (nondiabetic, $n=45$; type 2 diabetic, $n=10$ ) and non-human primates $(n=10 ; 5-30$ years) and from 15 mice aged 10 99 weeks. Total cellular LB content was estimated by threedimensional (3D) mathematical modelling.

Results LB area proportion was significantly correlated with age in human and non-human primates. The proportion of human LB-positive beta cells was significantly related to age, with no apparent differences in type 2 diabetes or obesity. LB content was low in human insulinomas $(n=5)$ and alpha cells and in mouse beta cells (LB content in mouse $<10 \%$ human). Using 3D electron microscopy and 3D mathematical modelling, the LB-positive human beta cells (representing aged cells) increased from $\geq 90 \%$ ( $<10$ years $)$ to $\geq 97 \%$ $(>20$ years) and remained constant thereafter.

Conclusions/interpretation Human beta cells, unlike those of young rodents, are long-lived. LB proportions in type 2 diabetes and obesity suggest that little adaptive change occurs in the adult human beta cell population, which is largely established by age 20 years.

Keywords Ageing · Human · Islet · Longevity · Mathematical modelling $\cdot$ Monkey $\cdot$ Mouse $\cdot$ Neogenesis . Pancreatic beta cell $\cdot$ Type 2 diabetes

\section{Abbreviations \\ 2D Two-dimensional \\ 3D Three-dimensional \\ EM Electron microscopy \\ LB Lipofuscin body}

\section{Introduction}

The aetiology of type 2 diabetes includes both genetic and environmental factors that affect the production of insulin from pancreatic islet beta cells and the sensitivity of peripheral tissues to insulin. Many of the new genetic markers for type 2 diabetes implicate aberrant development or production of beta cells in utero or in later life, or are associated with cell turnover/regeneration [1-3]. It has been hypothesised that the beta cell population flexibly adapts to insulin requirements and is normally determined by an equilibrium of apoptosis and neogenesis and/or replication of beta cells [4-7]. This recent concept of islet cell plasticity replaces the long-held view that cell number is largely established during embryogenesis and early life and remains relatively unchanged thereafter. Increased demand for insulin with increased insulin resistance/obesity would lead to a larger beta cell population; failure to expand beta cell number by replication and neogenesis and/or increased apoptosis would result in type 2 diabetes $[8,9]$. An increase in the beta cell population with increased demand for insulin in obesity is very evident in rodents [10] but is smaller and variable in obese humans $[11,12]$. The half-life of beta cells has been estimated to be $30-60$ days in young rodents ( $<1$ year old) on the basis of histological quantification of apoptotic and neogenic cells [9]. Using similar techniques, replication of human adult beta cells has been estimated to be tenfold less than that in adult mice $[4,11]$ and to be highest in children $<5$ years old [13]. Incorporation of BrdU into mouse islet cells decreases with age and becomes very low in animals at age 1 year [14], suggesting that the beta cell population becomes largely post-mitotic by 12 months. Nevertheless, extrapolation of cellular turnover and neogenesis in relation to onset of type 2 diabetes continues to be based on young mouse models [15].

Insulin secretion in non-diabetic humans decreases with age in vivo [16]. Ageing of tissues involves insulin/IGF-I signalling [17], and the 'free radical theory of ageing' [18] is supported by evidence of an age-related decrease in mitochondrial function [19]. Understanding the ageing of beta cells, which are highly dependent on ATP production for insulin secretion, is therefore of importance.

Few methods exist to determine the lifespan of cells. Telomere length is a marker for the number of cell divisions and is shorter in proliferative cells [20] compared with those of the brain, liver, kidney and heart, which are considered to be post-mitotic [21]. Recent innovative experiments to determine cell age by radiocarbon dating indicate that cortical neuronal life equals the life of the individual but intestinal cells are younger [22]. Lipofuscin bodies (LBs) are storage organelles of the lysosomal system and their accumulation in the cell is a feature of ageing in post-mitotic cells in mammalian and other species, particularly in neurons [23] and cardiac myocytes [24, 25]. An increase of 'lipid-storing vesicles' in beta cells with age has been described [26] but these were not identified as lipofuscin. The aims of this study were to determine if lipofuscin accumulation in human and non-human primate beta cells and other pancreatic cell types is age-related and could be used as a marker for longevity. These data were compared with that of aged mice. Using mathematical simulations we modelled the accumulation of LB in three dimensions (3D) and estimated the degree of ageing vs neogenesis and replication of beta cells over a wide age range in humans. The modelling was evaluated by quantitative volumetric morphometry of 3D electron microscopy (EM) of a human islet.

\section{Methods}

Human pancreatic tissue Human pancreatic tissue was obtained from the pancreatic islet donor programmes centred in Leiden and Brussels and from the Islet Transplant Unit in 
Oxford. Protocols were approved by Local and Regional Ethics Committees in Holland, Belgium and the UK. Human islets were prepared by collagenase digestion. Islet tissue was obtained from individuals aged $1-81$ years $(n=55)$. Donor BMI was known for 36 samples (mean $25.6 \pm 0.9[\mathrm{SE}] \mathrm{kg} / \mathrm{m}^{2}$; range $16-36 \mathrm{~kg} / \mathrm{m}^{2}$ ). Cause of death of the donors was trauma or cardiovascular disease and 45 donors had no history of diabetes; ten had documented evidence for type 2 diabetes. This large cohort includes data from 11 nondiabetic patients originating from the Brussels' cohort, which has been reported previously [26]. Human, non-malignant insulinoma specimens were obtained from surgical resections in Oxford and Brussels with permission from the Local Ethical Committees and the patients (individuals aged 3279 years, $n=5$ ).

Non-human primate pancreatic tissue Non-human primate pancreatic tissue was resected immediately post-mortem from macaque monkeys; animals aged 5-30 years had been bred and maintained in captivity according to US animal regulations, and the Institutional Animal Care and Use Committees.

Mouse islets Pancreatic tissue was prepared for EM from C57BL/6 mice aged 10-99 weeks $(n=15)$. Animal care conformed to the UK and Belgian regulations for care of laboratory animals and investigations conformed to the Guide for the Care and Use of Laboratory Animals published by the US National Institutes of Health (NIH publications No. 85-23, revised 1985). Mouse islets and tissue was processed for EM as described for human samples.

Electron microscopy Islet and pancreatic tissue was fixed in either $4.5 \%$ glutaraldehyde (wt/vol.) in cacodylate buffer $(\mathrm{pH}$ 7.3 ) or in $2.5 \%$ glutaraldehyde in phosphate buffer ( $\mathrm{pH} 7.2)$, post-fixed in osmium tetroxide ( $1 \% \mathrm{wt} / \mathrm{vol}$.) and embedded in Spurr's resin (Agar Scientific, Stansted, UK). Some specimens were embedded in LRGold resin (Agar Scientific) for immunolabelling for transmission EM. Acid phosphatase was localised using a modified Gomori reaction, as previously described [26]. Ultrathin sections were cut onto nickel grids and contrast enhanced with uranyl acetate and lead citrate. Immunogold localisation of the lysosomal enzyme cathepsin $\mathrm{D}$ was made using antibodies raised in rabbits $(1: 5,000)$ (DAKO, High Wycombe, UK) and Protein A gold $15 \mathrm{~nm}$ (Biocell, Cardiff, UK).

Quantification of LBs was made on EM images of 20-50 beta cells per specimen independently in Brussels and Oxford; in embedded pancreatic specimens beta cells were selected at random from cross-sections of at least two or three different islets having the typical islet structure of the 'dorsal pancreas' with very few cells containing pancreatic polypeptide. Thirtyfive samples collected for EM in Brussels consisted of 100,000 dispersed islet cells obtained following islet isolation.
Therefore, in these samples cells were derived from far more than two or three islets. LBs were defined as multivesicular structures, bounded by a membrane and containing both electron-lucent (lipid-like material) and a more electron-dense (pigmented) rim. Smaller ( $<6 \mathrm{~mm}$ diameter) secondary lysosomes containing homogeneous electron-dense material were not included in the analyses. The cross-sectional areas of the LBs were expressed in relation to the measured area of the cell cytoplasm and the number and size of LBs recorded for each cell.

Validation of the sampling of islet cells for LB content was done by assessing the reproducibility of the measurements in different batches of islet cells that were maintained in vitro for 2-8 days or for 10 weeks in vivo in a model of transplantation in nude mice (see Electronic Supplementary Material [ESM] for methods). For the alpha and beta cells, $60 \%$ of replicate measures had a $\mathrm{CV}<10 \%$ and $90 \%$ had a $\mathrm{CV}<20 \%$ (ESM Fig. 1). These data suggest that the method is robust and reproducible.

For 3D EM, fixed and osmicated islets from a human donor (aged 40 years) were embedded in Spurr's resin and prepared for serial sectioning and 3D imaging by scanning EM [27] (see ESM for methods).

Statistical analyses Statistical associations were made using linear or logarithmic regression $\left(\log _{e}\right)$ (correlation coefficient $r$ ). Multiple regression analysis was used to examine the association between accumulation of LBs (dependent variable) and age, BMI, sex or diabetes (independent variables).

Modelling the number and size of LBs in the beta cell Probability theory and mathematical formulas do not allow derivation of information in 3D from a two-dimensional (2D) picture. We therefore estimated the proportion of lipofuscincontaining beta cells and the number and size of LBs in 3D and their distribution throughout the cell by building a simplified 3D model in the program Mathematica (ESM Model 1 and Simulations 1-3). The programming characteristics of Mathematica allow rapid generation of a very large number of simulations, thus yielding high statistical confidence. These data were compared with micrographic images and morphometric data obtained from patients of different age categories. The input variables were adjusted until the output data fitted with the morphometric data. Volumetric data from the 3D EM analysis were compared with data predicted by mathematical modelling for that age.

\section{Results}

$L B$ content of beta cells increases with age Multivesicular LBs were apparent in human islet beta cells (Fig. 1a), alpha 


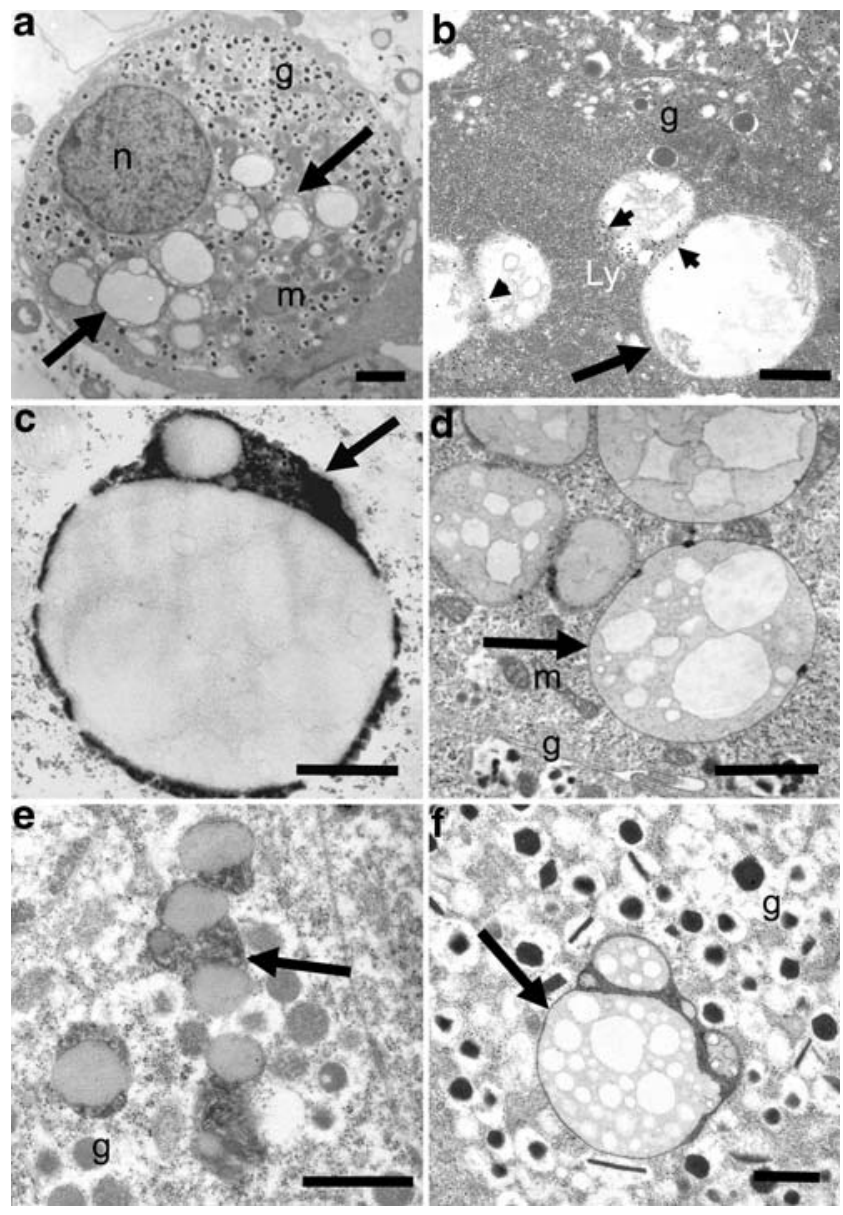

Fig. 1 LBs in human and non-human primate beta cells. a Human beta cells contained many LBs (arrows), which were morphologically discrete multivesicular bodies with lipid-containing electron-lucent and pigmented electron-dense bodies. b Ultrathin sections of human tissue embedded in LRGold resin immunogold-labelled for the lysosomal enzyme cathepsin D (arrowheads). Labelling was present in morphologically homogeneous secondary lysosomes (Ly) and at the margins of LBs (arrows). c Gomori reaction for acid phosphatase was visible as an electron-dense deposit at the margins of an LB in a human beta cell. d LBs in type 2 diabetic organ donor (aged 46 years) were not different from those in non-diabetic donors. e LBs in nonhuman primate beta cell. f LB in mouse beta cell (aged 68 weeks). g, insulin granule; m, mitochondria; $n$, nucleus; Ly, secondary lysosome labelled for cathepsin D. Arrows indicate LBs. Scale bars: a, d, e $1.0 \mu \mathrm{m} ; \mathbf{b}, \mathbf{c}, \mathbf{f} 0.5 \mu \mathrm{m}$

cells and some ductal epithelial cells (ESM Fig. 2), and were morphologically identical to 'lipid-storing vesicles' previously described [26] and lipofuscin in other organs [28]. Immunogold labelling demonstrated that the lysosomal serine protease, cathepsin D, was localised to electrondense and morphologically homogeneous secondary lysosomes and in the marginal regions of the multivesicular LBs (Fig. 1b); pre-embedding acid phosphatase labelling confirmed the association of these structures with the lysosomal system (Fig. 1c). The appearance of LBs was similar in all human individuals, and non-human primates (Fig. 1a, d, e).
Using the same techniques, LBs were identified with similar structural features in mouse islet beta cells (Fig. 1f) and human islet alpha and pancreatic ductal cells (ESM Fig. 2). LB content in islets from different donors was unchanged following culture for up to 8 days and 10 weeks transplantation in nude mice (ESM Fig. 1a-c). There was an increase in the beta cell content of LBs with increasing age of humans and non-human primates. The proportion of the beta cell area occupied by LBs in electron micrographs (LB area expressed as per cent of cytoplasmic area) was positively correlated with age in human beta cells $(r=0.86, p<0.0001$, Fig. 2a), increasing from $0.03 \%$ of cytoplasmic area for the youngest donor to $14 \%$ in the oldest. A similar correlation was seen in non-human primate beta cells $(r=0.88, p<0.001$, Fig. $2 b)$. An age-related increase in LB area proportion was seen in human alpha cells $(r=0.7, p<0.001)$ and ductal cells $(r=0.5$, $p<0.02)$, but this occurred at a much lower rate compared with beta cells from the same donors (Fig. 3a). The percentage of human beta cell sections which contained at least one LB (LB-positive cell sections) was positively correlated with age $(r=0.82, p<0.0001$, Fig. $2 \mathrm{c})$; the LBpositive proportion increased logarithmically from $7 \%$ (aged 1 year) to $100 \%$ (aged 52) (Fig. 2c).

LB area proportion in mouse beta cells was low $(<0.4 \%)$ (ten times less than that in human beta cells) and stable in animals $<1$ year old, but there was an increase in content in mice $>1$ year old (Fig. $3 \mathrm{~b} ; r=0.77, p<0.001$ ). The proportion of LB-positive cells increased with age in mice, reaching a maximum of $65 \%$ (aged $>1$ year) (Fig. $3 c ; r=0.50, p=0.055$ ).

The number of LBs per cell section also increased with age in both human (Fig. 2d) and non-human primates. These variables were not apparently different in the type 2 diabetic patients (aged 29-75 years) compared with non-diabetic participants (Fig. 2). When analysed separately, LB area proportion from the ten type 2 diabetic patients was also correlated with age $(r=0.64, p=0.04)$. There was no relationship of sex (data not shown) or BMI to LB area proportion or LB-positive cell proportion by linear regression (ESM Fig. 3). Using age and BMI as independent variables in a multiple regression model, age was strongly correlated with LB number, LB area proportion or LB-positivity (standardised coefficients $0.74-0.85, p<0.0001$ ) but BMI was not (coefficients $0.07-0.12, p>0.3$ ). Similarly, in a multiple-regression model with age, BMI, sex and diabetic status as independent variables, LB content was correlated with age (standardised coefficients $0.74-0.85, p<0.0001$ ), while none of the other variables showed significant association (with standardised coefficients for diabetic status $0.02-0.08, p>0.5)$.

In human insulinoma cells, both LB area proportion and percentage of LB-positive cell sections were clearly different from that in human beta cells of donors at equivalent ages (Fig. 2a, c). The area proportion in insulinoma cells was low 
Fig. 2 Morphometric analysis of LB content of beta cells. a LB area proportion (LB area as per cent of cytoplasmic area) increased linearly with age in human beta cells, $r=0.86, p<$ 0.0001 . b Linear increase of LB area proportion with age in non-human primate beta cells, $r=0.88, p<0.001$. c The percentage of human beta cells containing at least one cross-section of an LB (LB-positive cells) increased with age, $r=0.82, p<0.0001$. d The number of LBs in the human beta cell cytoplasmic section also increased with age, $r=0.68, p<0.0001$. LB proportions in insulinomas resected from patients of different ages were low. Diamonds, non-diabetic individuals/ animals; squares, type 2 diabetic patients; triangles, human insulinomas resected from patients of the indicated ages

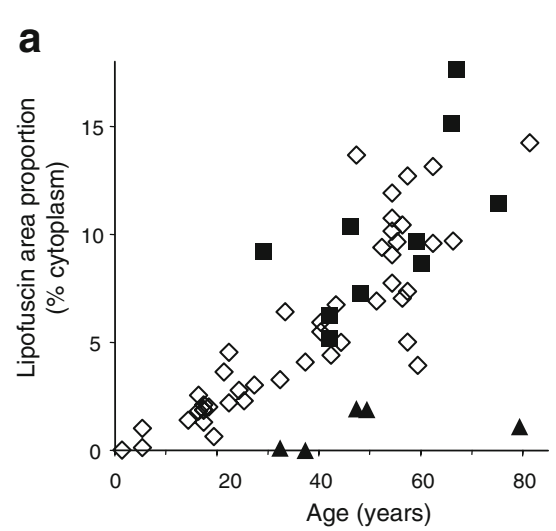

b

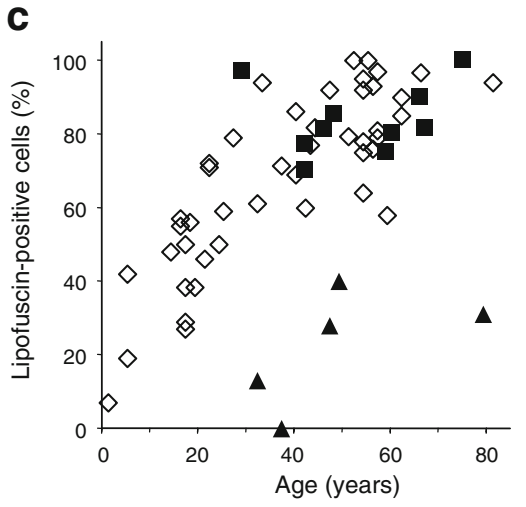

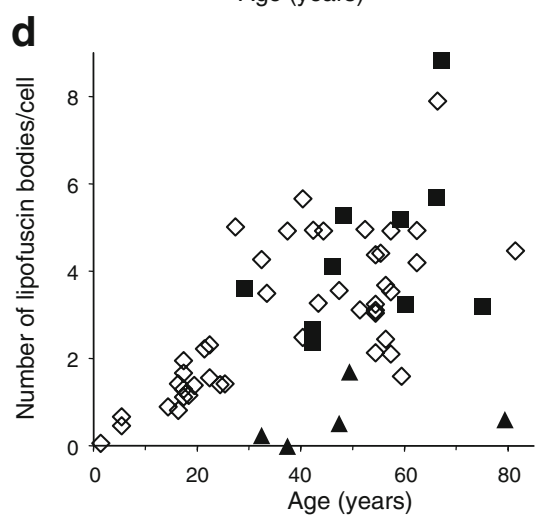

$(<2 \%)$ at all ages of patients examined $(32-79$ years at surgery). At aged 80 , the area proportion was $1 \%$ in insulinoma cells compared with $14 \%$ in normal beta cells, and the fraction of LB-positive cell sections was $31 \%$ in insulinoma compared with $94 \%$ in normal beta cells. In one patient (aged 47), both tumour and pancreatic islet cells were examined and the LB area proportion in insulinoma cells was $40 \%$ of that found in beta cells.

The LB population distribution changed in beta cells with ageing (ESM Fig. 4a, b). The likelihood of detecting a human beta cell with few and small LBs in the section became low after the second decade; in insulinoma cells both LB area proportion and percentage of LB-positive cell sections were clearly different from those in beta cells of donors at equivalent ages and resembled more closely those of donors $<10$ years old (Fig. 2a, c; ESM Fig. 4).

Mathematical modelling demonstrated that the beta cell population is established by age 20 Data determined by morphometry from an ultrathin $(60-100 \mathrm{~nm}) 2 \mathrm{D}$ EM section do not represent the total lipofuscin content of the cell. To estimate the proportion of LB-positive beta cells and the number and size of LBs in 3D, a simplified 3D model was constructed in Mathematica (provided in ESM Model 1) that simulates LB distribution in cells (Fig. 4a and ESM Simulations 1-3) and then sections the cell and quantifies 2D LB content. Mean values of the morphometric data for each donor decade were calculated (Fig. 5a, c, e and ESM
Table 1) and used for comparison with the simulations (Fig. 5b, d, f). In the model, the LB area proportion increased with age from $0.04 \%$ of cytoplasmic area for the youngest donor to $15 \%$ in the oldest (Fig. 5 b). The total volume of an organelle is strongly correlated to the total area in a section (the Cavalieri principle). Calculation of the 3D LB content from the 2D data showed that, in the oldest individuals, the total volume of LBs reached $35 \%$ of the cytoplasmic volume (Fig. 5b and ESM Table 1). According to the model, the insulinoma cells contained tenfold fewer and slightly smaller LBs compared with normal beta cells. LBs were also fewer and smaller in beta cells from old mice (ESM).

The modelled data corresponded well with the observed logarithmic increase in the percentage of LB-positive human beta cell sections per age category (Fig. $5 \mathrm{c}$, d); the number of LBs per cell section (2D) increased progressively with age from 0.2 to 5 (Fig. 5f). This fitted with the measured data, which were more variable (Figs. $2 \mathrm{~d}$ and $5 \mathrm{e}$ ). According to the model, the total number of LBs per cell in $3 \mathrm{D}$ does not increase very much with age, from ten per cell at young ages to about 25 per cell in the older age groups (ESM Table 1); the increased probability of sectioning lipofuscin results largely from the increased size of the bodies. The model showed that the percentage of beta cells containing LBs in 3D is $89 \%$ at aged 1 year, $95 \%$ at 5 years, $97 \%$ from 20 years on and $98 \%$ after 50 (Fig. $5 \mathrm{~d}$ ). This suggests that a very high proportion of beta cells are long-lived even in teenagers and young adults. 

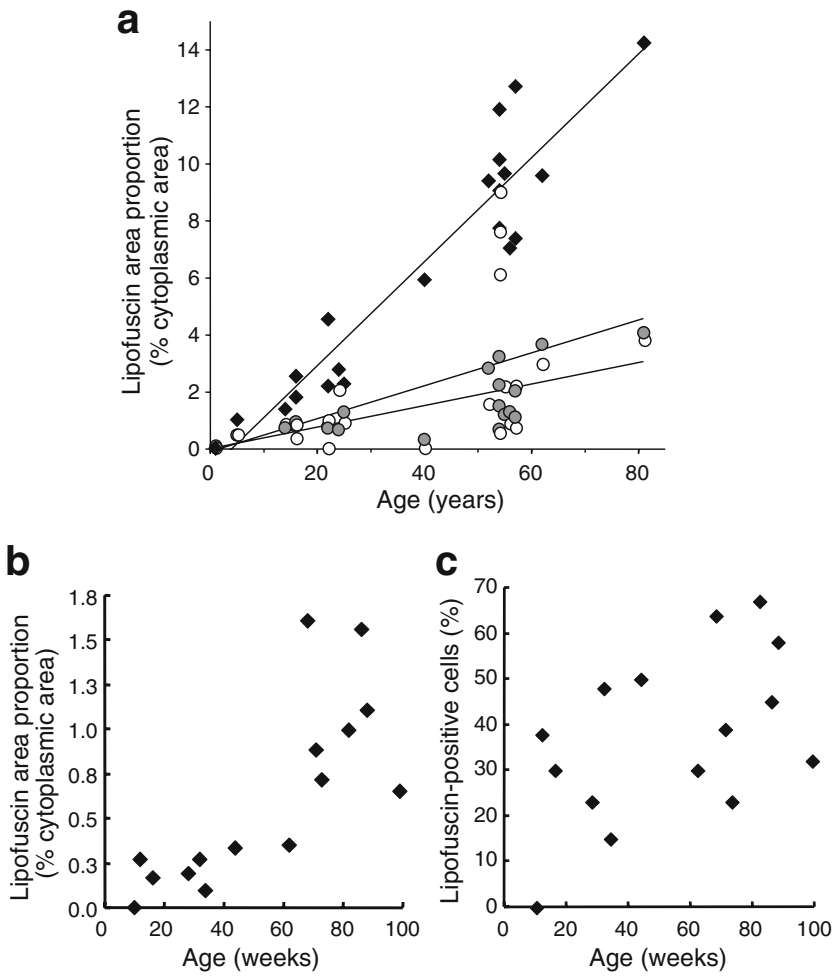

Fig. 3 a Age-related distribution of LBs in alpha and ductal cells. Alpha cells (grey circles; glucagon secreting and identified by electron-dense granules without an electron-lucent halo, $n=21$ ) and ductal epithelial cells (white circles; non-granulated epithelial cells) were present in the islet digest $(n=21)$. The proportion of cytoplasmic area occupied by LBs in alpha cells was four- to tenfold less than that seen in beta cells (diamonds) from the same islet preparations but increased with age $(r=0.74, p<0.0001)$. Ductal cells had an even smaller population of LBs but there was a significant increase in the cytoplasmic proportion with age $(r=0.5, p<0.02)$. b, c LB content in mouse beta cells. b Lipofuscin area proportion (as per cent of cytoplasmic area) in relation to mouse age (weeks); the LB proportion was a tenth of that found in human cells and was higher in mice $>$ 50 weeks old. $\mathbf{c}$ LB-positive cell proportion increased with mouse age

Preliminary 3D modelling of the data from five older mice where the LBs were larger and more numerous demonstrated that after 12 months, a mouse beta cell contains approximately seven LBs (compared with 25 in human beta cells after age 50 years and between two and four in human insulinomas). These LBs occupy $2-4 \%$ of the cytoplasmic volume of a mouse beta cell (compared with $20 \%$ in human beta cells and $0.5-4 \%$ in insulinomas).

Validation of the mathematical model from 3D EM Comparisons were made of the mathematical predictions and area and volume proportion derived from the 3D EM. LB area proportion (in 2D) was estimated by automatic imaging in scanned serial images. LB area proportion was $5.5 \%$, and LB volume proportion was $9.4 \%$ in a specimen from a 40 -year-old individual. These 3D imaging data are very similar to the values for this age predicted by mathematical modelling (Fig. 5 and ESM Table 1).

Estimation of LB-positive cell proportion in 3D was made using the images in Fig. 4c. These images represent a traverse of $\sim 50 \%$ of a beta cell diameter $(8 \mu \mathrm{m})$ and demonstrate that measurements made from a single cell section underestimate LB content. In one section (Fig. 4c), $42 \%$ of cells were LB-positive. However, LBs could be identified in the other cells in consecutive images (Fig. $4 \mathrm{~d}-\mathrm{j}$ ), resulting in a total LB-positive cell proportion of $98 \%$, which is directly comparable to the mathematical prediction (Fig. 5).

\section{Discussion}

The positive linear correlation between age and the LB area proportion in human and non-human primate beta cells is similar to data derived from LB distribution in post-mitotic cells in other organs such as the human brain $[23,29,30]$ and rat cardiac myocytes and neurons [24, 31, 32] and extends the observations made previously on 'lipid-storing vesicles' [26]. Lipofuscin is similar in appearance to ceroid, which accumulates rapidly as a result of pathological conditions such as neurodegenerative and genetic diseases but is not age-related [33]. LBs in beta cells were immunopositive for the lysosomal proteases cathepsins $\mathrm{B}$ and $\mathrm{D}$, indicating their relationship with the lysosomal system. Lipofuscin represents the end stage of intracellular lysosomal degradation; senescent or damaged mitochondria, membranes and secretory granules are incorporated into lysosomes by autophagy [34, 35], but increased peroxidation and cross-linking renders lipids and proteins in the lysosomes resistant to lipases and proteases. This results in formation of LBs as waste-storage organelles [34], which, in many non-proliferating cell types, cannot be exported. Lipofuscin content was low and unrelated to age in the proliferating human insulinoma cells, demonstrating continuous dilution of LBs into daughter cells, and a short age-span of these cells. Our data from primate beta cells suggest that, like cardiac and skeletal muscle and neurons, human islet beta cells are post-mitotic and have a very long lifespan. Alpha cells and non-granulated ductal cells also exhibited an age-related increase in LB population. However, the rate of accumulation was lower. The LB proportion in mouse beta cells, even at ages $>12$ months, was very low (one-tenth of that found in primate cells). It remains to be conclusively determined whether this is merely because of the different lifespans of the mouse and man, or whether beta cells in the two species have different intrinsic characteristics contributing to LB formation and accumulation, with cell replication and neogenesis counteracting the latter. 
Fig. $43 \mathrm{D}$ modelling and 3D imaging of beta cells. a 3D mathematical model of LB distribution. Within the cell, the large sphere represents the nucleus and the smaller opaque spheres are the LBs. b 3D image of part of a human islet from a 40-year-old donor examined by 3D EM. B, beta cells; A, alpha cell; D, delta cell. LBs are electron-dense spherical structures (arrows) sometimes with lipid-like electron-lucent inclusions. Scale bar $10 \mu \mathrm{m}$. c-j Eight serial images through part of a human islet to demonstrate LB distribution.

Some LBs seen in more than one section are identified by red, green and yellow arrows (sections $1 \mu \mathrm{m}$ apart). $\mathbf{c}$, nuclei; $n^{*}$ identifies the nuclei of LB-positive cells within this section. In this section, $42 \%$ of nucleated cells contained LBs. $\mathbf{c}-\mathbf{j}$ the LB-positive cell proportion in all eight adjacent sections was $98 \%$. Scale bar, $8 \mu \mathrm{m}$
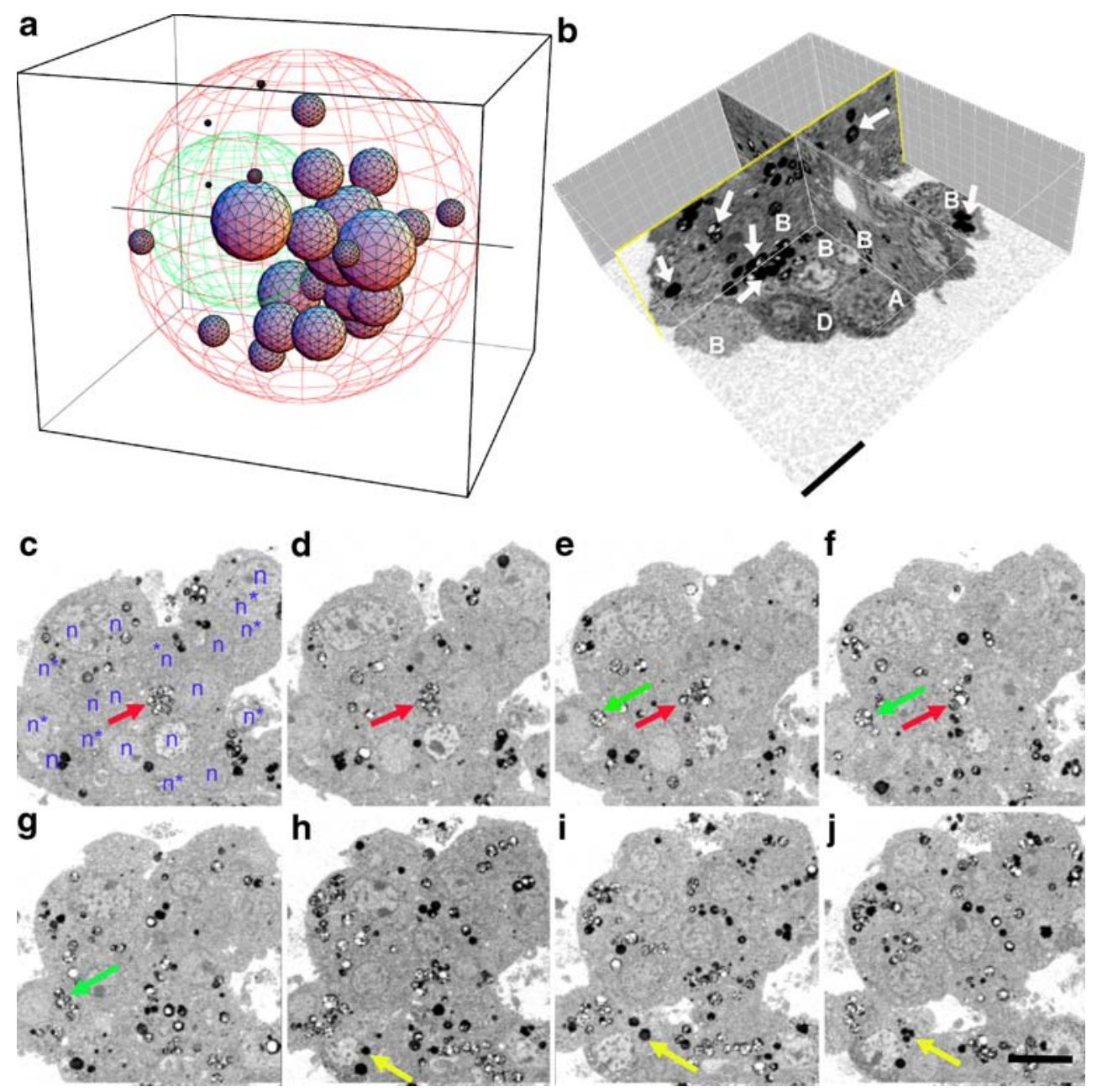

The low proportion of human beta cells containing no LBs, implying a short life history (11\% at aged 1 year, $5 \%$ at 5 years and $2-3 \%$ in adult life), suggests that neogenesis or transdifferentiation of beta cells from ductal or other precursors is uncommon in normal, obese and type 2 diabetic human pancreas. Dividing beta cells are most numerous in children $<5$ years of age [13]. Our data on longevity are derived from viable cells in human islets in situ in the pancreas or in vitro following islet isolation; apoptotic or damaged cells were not included in our analyses and no marker for cell division was available for use with EM. Thus, information relating to cell death cannot be derived. The higher rate of LB accumulation with age in beta cells compared with alpha cells in the same individual could represent differences in cell turnover or result from different degrees of lipid uptake [26, 36], mitochondrial turnover or disposal of autophagic lysosomal material in the two cell types [30]. The number and size of LBs in murine beta cells at 12 months old was substantially lower than those of beta cells of humans aged 50 years; this would be consistent with a lower proliferation rate in humans compared with that in mice $<12$ months old [37-39]. Evidence for a post-mitotic and non-regenerative population of adult human beta cells is provided from observations that human beta cells are resistant to proliferation in vitro compared with rodent cells under the same conditions [38]. Furthermore, there was no evidence for islet neogenesis in man following partial pancreatectomy [40], in contrast to increased beta cell proliferation following pancreatectomy or pancreatic injury in younger rodents $[7,15,41]$. However, this plasticity is altered in older mice ( $>12$ months) where beta cell proliferative responses to pancreatectomy, glucagon-like peptide-1 analogue administration and high-fat diet were reduced compared with younger animals [39, 42]. In human islets, there is an age-related decreased expression of the beta cell master transcription factor pancreatic duodenal homeobox factor (donors aged 17-74 years), indicating both a decreased capacity with age for cellular proliferation (decreased plasticity) and reduced insulin formation and secretion [43].

Increased islet size (but not islet number) is associated with obesity in rodents [10] and a small increase in the beta cell population in humans is proposed [4, 12, 44], implicating increased cell proliferation. However, in the present data, 

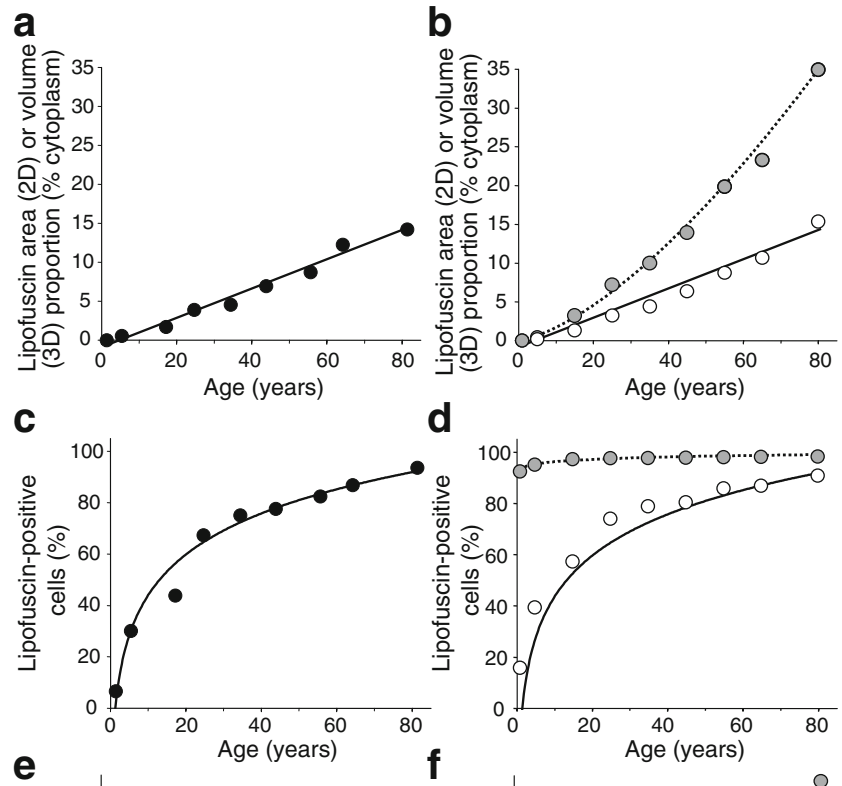

d
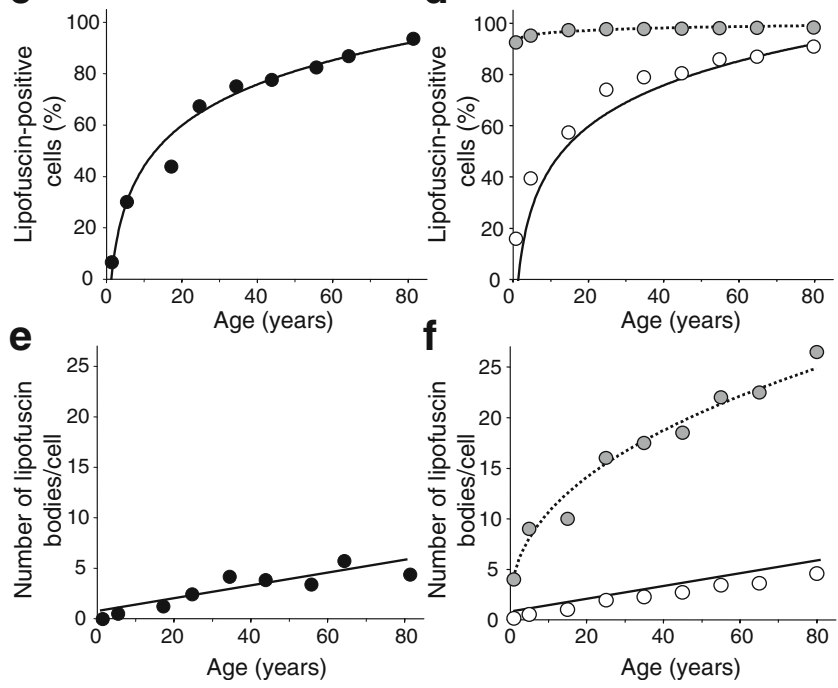

Fig. 5 Comparison of the mathematical model with the morphometric beta cell lipofuscin content. a Linear correlation between LB area proportion (per cent of cytoplasmic area) in human beta cells and donor age. Symbols are means of data in decade age categories. b Mathematical simulations of the 2D LB area proportion based on decade means (white circles) showing close fitting with morphometric data. Black regression line is for experimental data of panel a. Grey circles represent 3D LB volume (per cent of cytoplasmic volume) estimated by the model (dotted regression line for modelled 3D data, coefficient $r=1.00$ ). c Logarithmic increase with donor age of LBpositive cell sections. Black symbols are means of data in decade age categories. d Mathematical simulations of the proportion of LBpositive cells based on decade means (2D, white circles) showing close fitting with morphometric data. The black regression line is for experimental data of panel c. Grey circles represent the percentage of beta cells containing at least one LB in $3 \mathrm{D}$ as estimated in the model (dotted regression line, $r=0.98$ ). This suggests that almost all cells are LB-positive from an early age. e Increase with donor age of the number of LBs per beta cell section. Black symbols are means of data in decade age categories. $\mathbf{f}$ Mathematical simulations of the number of LBs per cell section (2D, white circles) in the model. Regression line is for experimental data of panel e. Grey circles represent the number of LBs per cell in 3D (dotted regression line, $r=0.99$ )

there was no relationship of donor BMI (range $16-36 \mathrm{~kg} / \mathrm{m}^{2}$ ) to LB distribution. Similarly, LB accumulation was similar in men and women; pregnancy in rodents is associated with increased beta cells [45]. Our observations do not exclude the potential of ageing beta cells for division, which could be activated by external stimuli, as demonstrated in young rodents $[15,46,47]$. However, if in vivo the increased demand for insulin in obesity or the stimulus of hyperglycaemia in diabetes had resulted in activation of beta cell neogenesis [46] or beta cell division [7], a population of younger cells with lower LB content in obese and diabetic patients should have been apparent. Equally, if normally there was a small $(2 \%$ is predicted by the mathematical model) but constant turnover of beta cells that was reduced in diabetes, our hypothesis would predict an increased population of aged viable cells with higher than expected LB content. However, no major difference of LB population in diabetes was apparent. Evidence for an age-related decrease in an adaptive proliferative response in islets of mice $>2$ months old has been described [39]. Similarly, in human organ donors, an age-related decrease of replicating cells has been interpreted as evidence of decreased adaptability [48]. These data taken together suggest that, whereas the population of islet cells is established and not plastic in man after about age 20 years, this point is reached in mice at approximately 1 year; adaptability of young mice to obesity, pregnancy and pancreatic damage may model the potential plasticity of human islets in individuals $<20$ years of age and not the relatively stable condition in adults.

Whilst incorporation of damaged or senescent cellular material into lysosomes and lipofuscin is a protective cellular response for the ageing cell, accumulation of metals, reactive oxygen species and degradation products of autophaged mitochondria in the lysosomal system may not be entirely a bystander activity [49]; slow accumulation of lipofuscin in the ageing beta cells, whilst not toxic to the cells, could progressively create an increased sensitivity to oxidative damage and contribute to cytotoxic events.

The regulation of insulin secretion is highly dependent on ATP production and there is an age-related decline in both mitochondrial function $[19,50]$ and glucose-stimulated insulin secretion $[16,50]$. Many of the susceptibility genes associated with type 2 diabetes by genome-wide investigations are identified by cancer research as regulators of cell turnover or regeneration [1], but the function of most of these factors in the beta cell are unknown and could be unrelated to cell proliferation, or they might only play a role early in life when the islet cell population is established [3]. Our data suggest that, as with neurons, adult human beta cells are long lived and there is little evidence for substantial islet cell turnover or plasticity in response to insulin demand. This differs from the situation in the commonly used model for diabetes, young rodents. The cellular longevity has implications for determination of causal factors for onset of type 2 diabetes in susceptible individuals and development of therapies.

Acknowledgements We are grateful to the following for funding this study: The Wellcome Trust (A. Clark, J. H. Gunter.), Diabetes UK (A. Clark), the European Union (Integrated Project EuroDia LSHM- 
CT-2006-518153 in the Framework Programme 6 (FP6) and Collaborative Project CEED3 in the Framework Programme 7 (FP7), to M. Cnop), the Fonds National de la Recherche Scientifique (FNRS) and Fonds de la Recherche Scientifique Médicale (FRSM) (M. Cnop), Diabetes Research and Wellness Foundation (S. J. Hughes) and the National Institute on Aging NO1 AG-3-1012 (BH). G. V. Walls is supported by an MRC Clinical Training Fellowship, and provision of old mice was supported by an MRC Programme Grant to R. Thakker (OCDEM, Oxford, UK) and by a grant to A. Clark from the Wellcome Trust. We thank L. Scott and S. Rodgers (Department of Physiology, Anatomy and Genetics, Oxford, UK) for technical assistance with EM, J.-C. Hannaert (Diabetes Research Centre, Vrije Universiteit Brussel, Belgium) for help with morphometry, N. Bodkin (Physiology, Obesity, and Diabetes Research Center, University of Maryland, Baltimore, MD, USA) for assistance with non-human primate samples, P. Rorsman (OCDEM) for critical comments on the manuscript, and F. Grandsard (Department of Mathematics, Vrije Universiteit Brussel, Brussels, Belgium) for discussions on mathematics and probability theory. Part of this work was included in the $\mathrm{PhD}$ thesis of M. Cnop whilst working in the Diabetes Research Center, Vrije Universiteit, Brussel, under the supervision of D. Pipeleers and supported by a Fonds voor Wetenschappelijk Onderzoek Aspirant fellowship. We are grateful to C. Genoud and S. Monteith of Gatan, Pleasanton, CA, USA for their considerable help in preparation and interpretation of the 3D EM.

Duality of interest The authors declare that there is no duality of interest associated with this manuscript.

\section{References}

1. McCarthy MI, Hattersley AT (2008) Learning from molecular genetics: novel insights arising from the definition of genes for monogenic and type 2 diabetes. Diabetes 57:2889-2898

2. Meier JJ (2009) Linking the genetics of type 2 diabetes with low birth weight: a role for prenatal islet maldevelopment? Diabetes 58:1255-1256

3. Freathy RM, Bennett AJ, Ring SM et al (2009) Type 2 diabetes risk alleles are associated with reduced size at birth. Diabetes 58:1428-1433

4. Butler AE, Janson J, Bonner-Weir S, Ritzel R, Rizza RA, Butler PC (2003) Beta-cell deficit and increased beta-cell apoptosis in humans with type 2 diabetes. Diabetes 52:102-110

5. Weir GC, Bonner-Weir S (2004) Five stages of evolving beta-cell dysfunction during progression to diabetes. Diabetes 53(Suppl 3): S16-S21

6. Ritzel RA, Butler AE, Rizza RA, Veldhuis JD, Butler PC (2006) Relationship between beta-cell mass and fasting blood glucose concentration in humans. Diabetes Care 29:717-718

7. Dor Y, Brown J, Martinez OI, Melton DA (2004) Adult pancreatic beta-cells are formed by self-duplication rather than stem-cell differentiation. Nature 429:41-46

8. Bonner-Weir S (2001) Beta-cell turnover: its assessment and implications. Diabetes 50(Suppl 1):S20-S24

9. Finegood DT, Scaglia L, Bonner-Weir S (1995) Dynamics of betacell mass in the growing rat pancreas. Estimation with a simple mathematical model. Diabetes 44:249-256

10. Bock T, Pakkenberg B, Buschard K (2003) Increased islet volume but unchanged islet number in ob/ob mice. Diabetes 52:17161722

11. Butler PC, Meier JJ, Butler AE, Bhushan A (2007) The replication of beta cells in normal physiology, in disease and for therapy. Nat Clin Pract Endocrinol Metab 3:758-768
12. Rahier J, Guiot Y, Goebbels RM, Sempoux C, Henquin JC (2008) Pancreatic beta cell mass in European subjects with type 2 diabetes. Diabetes, Obesity and Metabolism 10:32-42

13. Meier JJ, Butler AE, Saisho Y et al (2008) Beta-cell replication is the primary mechanism subserving the postnatal expansion of beta-cell mass in humans. Diabetes 57:1584-1594

14. Teta M, Long SY, Wartschow LM, Rankin MM, Kushner JA (2005) Very slow turnover of beta-cells in aged adult mice. Diabetes 54:2557-2567

15. Xu X, D'Hoker J, Stange G et al (2008) Beta cells can be generated from endogenous progenitors in injured adult mouse pancreas. Cell 132:197-207

16. Basu R, Breda E, Oberg AL et al (2003) Mechanisms of the ageassociated deterioration in glucose tolerance: contribution of alterations in insulin secretion, action, and clearance. Diabetes 52:1738-1748

17. Gems D, Partridge L (2008) Stress-response hormesis and aging: "that which does not kill us makes us stronger". Cell Metab 7: 200-203

18. Harman D (1956) Aging: a theory based on free radical and radiation chemistry. J Gerontol 11:298-300

19. Bonawitz ND, Shadel GS (2007) Rethinking the mitochondrial theory of aging: the role of mitochondrial gene expression in lifespan determination. Cell Cycle 6:1574-1578

20. Hastie ND, Dempster M, Dunlop MG, Thompson AM, Green DK, Allshire RC (1990) Telomere reduction in human colorectal carcinoma and with ageing. Nature 346:866-868

21. Takubo K, Nakamura K, Izumiyama N et al (2000) Telomere shortening with aging in human liver. J Gerontol A Biol Sci Med Sci 55:B533-B536

22. Spalding KL, Bhardwaj RD, Buchholz BA, Druid H, Frisen J (2005) Retrospective birth dating of cells in humans. Cell 122: $133-143$

23. Benavides SH, Monserrat AJ, Farina S, Porta EA (2002) Sequential histochemical studies of neuronal lipofuscin in human cerebral cortex from the first to the ninth decade of life. Arch Gerontol Geriatr 34:219-231

24. Schmucker DL, Sachs H (2002) Quantifying dense bodies and lipofuscin during aging: a morphologist's perspective. Arch Gerontol Geriatr 34:249-261

25. Terman A, Dalen H, Eaton JW, Neuzil J, Brunk UT (2004) Aging of cardiac myocytes in culture: oxidative stress, lipofuscin accumulation, and mitochondrial turnover. Ann N Y Acad Sci 1019:70-77

26. Cnop M, Grupping A, Hoorens A, Bouwens L, Pipeleers-Marichal M, Pipeleers D (2000) Endocytosis of low-density lipoprotein by human pancreatic beta cells and uptake in lipid-storing vesicles, which increase with age. Am J Pathol 156:237-244

27. Denk W, Horstmann H (2004) Serial block-face scanning electron microscopy to reconstruct three-dimensional tissue nanostructure. PLoS Biol 2:e329

28. De Duve C, Pressman BC, Gianetto R, Wattiaux R, Appelmans F (1955) Tissue fractionation studies. 6. Intracellular distribution patterns of enzymes in rat-liver tissue. Biochem J 60:604-617

29. Mann DM, Yates PO, Stamp JE (1978) The relationship between lipofuscin pigment and ageing in the human nervous system. J Neurol Sci 37:83-93

30. Sulzer D, Mosharov E, Talloczy Z, Zucca FA, Simon JD, Zecca L (2008) Neuronal pigmented autophagic vacuoles: lipofuscin, neuromelanin, and ceroid as macroautophagic responses during aging and disease. J Neurochem 106:24-36

31. Savitha S, Naveen B, Panneerselvam C (2007) Carnitine and lipoate ameliorates lipofuscin accumulation and monoamine oxidase activity in aged rat heart. Eur J Pharmacol 574:61-65

32. Porta E, Llesuy S, Monserrat AJ, Benavides S, Travacio M (1995) Changes in cathepsin B and lipofuscin during development and aging in rat brain and heart. Gerontology 41(Suppl 2):81-93 
33. Seehafer SS, Pearce DA (2006) You say lipofuscin, we say ceroid: defining autofluorescent storage material. Neurobiol Aging 27: 576-588

34. Kurz T, Terman A, Brunk UT (2007) Autophagy, ageing and apoptosis: the role of oxidative stress and lysosomal iron. Arch Biochem Biophys 462:220-230

35. Borg LA, Schnell AH (1986) Lysosomes and pancreatic islet function: intracellular insulin degradation and lysosomal transformations. Diabetes Res 3:277-285

36. Grupping AY, Cnop M, Van Schravendijk CF, Hannaert JC, Van Berkel TJ, Pipeleers DG (1997) Low density lipoprotein binding and uptake by human and rat islet beta cells. Endocrinology 138:4064-4068

37. Scharfmann R (2008) Expanding human beta cells. Diabetologia 51:692-693

38. Parnaud G, Bosco D, Berney T et al (2008) Proliferation of sorted human and rat beta cells. Diabetologia 51:91-100

39. Rankin MM, Kushner JA (2009) Adaptive beta-cell proliferation is severely restricted with advanced age. Diabetes 58:1365-1372

40. Menge BA, Tannapfel A, Belyaev O et al (2008) Partial pancreatectomy in adult humans does not provoke beta-cell regeneration. Diabetes 57:142-149

41. Peshavaria M, Larmie BL, Lausier J et al (2006) Regulation of pancreatic beta-cell regeneration in the normoglycemic $60 \%$ partial-pancreatectomy mouse. Diabetes 55:3289-3298
42. Tschen SI, Dhawan S, Gurlo T, Bhushan A (2009) Age-dependent decline in beta-cell proliferation restricts the capacity of beta-cell regeneration in mice. Diabetes 58:1312-1320

43. Maedler K, Schumann DM, Schulthess F et al (2006) Aging correlates with decreased beta-cell proliferative capacity and enhanced sensitivity to apoptosis: a potential role for Fas and pancreatic duodenal homeobox-1. Diabetes 55:2455-2462

44. Yoon KH, Ko SH, Cho JH et al (2003) Selective beta-cell loss and alpha-cell expansion in patients with type 2 diabetes mellitus in Korea. J Clin Endocrinol Metab 88:2300-2308

45. Parsons JA, Brelje TC, Sorenson RL (1992) Adaptation of islets of Langerhans to pregnancy: increased islet cell proliferation and insulin secretion correlates with the onset of placental lactogen secretion. Endocrinology 130:1459-1466

46. Bouwens L, Rooman I (2005) Regulation of pancreatic beta-cell mass. Physiol Rev 85:1255-1270

47. Bonner-Weir S, Weir GC (2005) New sources of pancreatic betacells. Nat Biotechnol 23:857-861

48. Reers C, Erbel S, Esposito I et al (2009) Impaired islet turnover in human donor pancreata with aging. Eur J Endocrinol 160:185-191

49. Terman A, Brunk UT (2006) Oxidative stress, accumulation of biological 'garbage', and aging. Antioxid Redox Signal 8: 197-204

50. Ihm SH, Matsumoto I, Sawada T et al (2006) Effect of donor age on function of isolated human islets. Diabetes 55:1361-1368 